\title{
Physical activity profile of students in Mansoura University, Egypt
}

A-H. El-Gilany, ${ }^{7}$ K. Badawi, ${ }^{2}$ G. El-Khawaga ${ }^{1}$ and N. Awadalla ${ }^{3}$

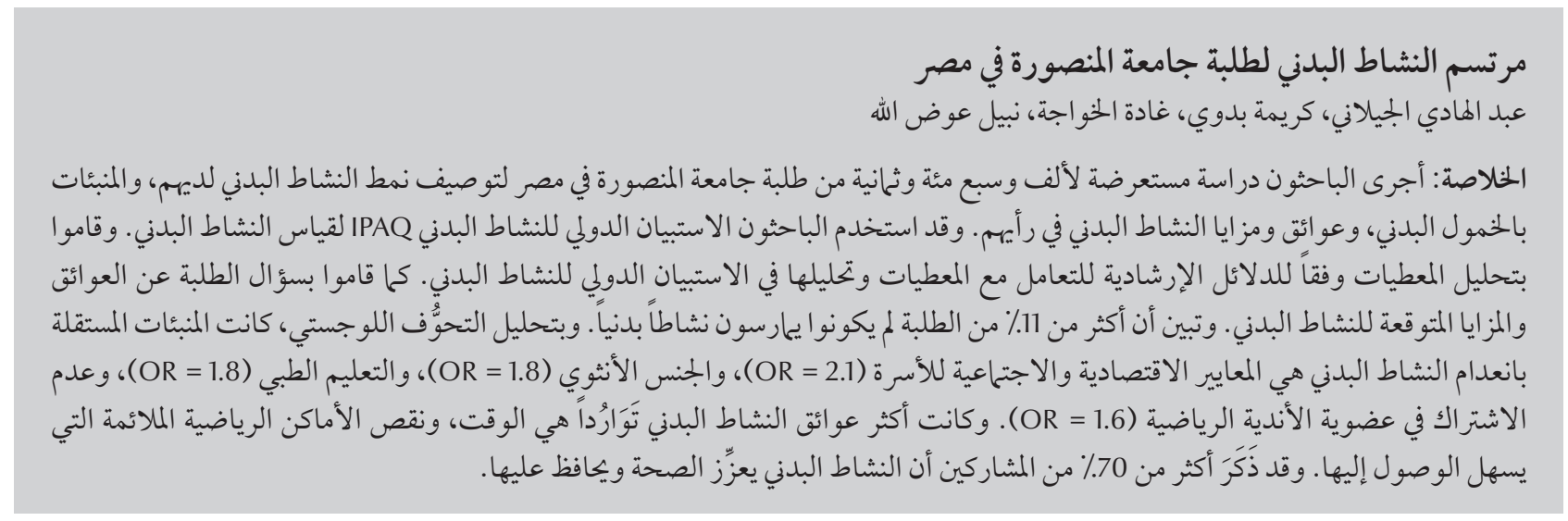

ABSTRACT A cross-sectional study was carried out on 1708 students from Mansoura University, Egypt, to describe the pattern of physical activity, predictors of physical inactivity and perceived barriers to and benefits of physical activity. The International Physical Activity Questionnaire (IPAQ) was used to measure physical activity. Data were analysed according to the guidelines for data processing and analysis of the IPAQ. Perceived barriers to and potential benefits of physical activity were asked for. More than $11 \%$ of students were physically inactive. On logistic regression analysis, the independent predictors of physical inactivity were high socioeconomic standard of the family (OR 2.1), female sex (OR 1.8), medical education (OR 1.8) and non-membership in sports clubs (OR 1.6). The most frequent barriers to physical activity were time limitation and lack of accessible and suitable sporting places. More than $70 \%$ of the participants stated that physical activity promotes and maintains health.

\section{Profil de l'activité physique des étudiants de l'Université de Mansoura (Égypte)}

RÉSUMÉ Une étude transversale a été conduite auprès de 1708 étudiants de l'Université de Mansoura (Égypte) pour décrire les caractéristiques de leur pratique sportive, les obstacles et les avantages perçus en la matière et les facteurs prédictifs de l'inactivité physique. Le questionnaire international sur l'activité physique (IPAQ) a été utilisé, et les informations ont été analysées conformément aux directives sur le traitement et l'analyse des données de ce questionnaire. Les étudiants ont été interrogés sur leur perception des obstacles et avantages potentiels de la pratique d'une activité physique. Plus de $11 \%$ des étudiants étaient physiquement inactifs. Selon une analyse de régression logistique, les facteurs prédictifs indépendants de l'inactivité physique étaient les suivants : statut socioéconomique familial élevé (O.R. 2,1), sexe féminin (O.R. 1,8), formation médicale (O.R. 1,8) et absence d'inscription dans un club de sport (O.R. 1,6). Les obstacles les plus fréquents à l'activité physique étaient les contraintes de temps et l'absence de lieux accessibles et adéquats pour la pratique d'un sport. Plus de $70 \%$ des participants ont affirmé que l'activité physique favorisait durablement une bonne santé.

${ }^{7}$ Public Health Unit; ${ }^{3}$ Occupational Medicine Unit, Department of Community Medicine, College of Medicine; ${ }^{2}$ Students' Hospital, Mansoura University, Mansoura, Egypt (Correspondence to A-H El-Gilany: ahgilany@gmail.com; ahgilany@hotmail.co.uk).

Received: 15/11/09; accepted: 25/02/10 


\section{Introduction}

Health-enhancing physical activity is that which benefits health and functional capacities without harm or risk. This term includes the full range of human movement, such as competitive sports and exercise, active hobbies, cycling or the physical activities of daily living [1-3]. Physical activity is the key strategy for reducing the risk of chronic diseases. Regular physical activity helps build and maintain healthy bone and muscle, reduces the risk of developing obesity, reduces feelings of depression and anxiety and promotes psychological well-being [4-8].

In his systematic review on the prevalence of university students' participation in physical activity of 19 studies from 27 countries, not including Egypt, Irwin concluded that more than half the university students in the United States of America (USA) and Canada were not active enough to gain health benefit [9]. Internationally the same was true, with Australian students having the highest level of sufficient activity. Other international studies concluded that the majority of university students were insufficiently physically active $[10,11]$.

Physical activity habits during adolescence and youth are likely to be important influences on habitual physical activity throughout adult life [12]. Opportunities for physical activity are largely determined by social, economic, and cultural factors as well as physical environments that influence access, availability and utilization [13].

To the best of authors' knowledge, no studies have been done to assess physical activity pattern among the Egyptian population in general and specifically among university students. The objectives of this study were to assess the levels of physical activity, study predictors of physical inactivity, and perceived barriers to and benefits of physical activity among students at Mansoura University, Egypt. Such studies could pave the way for planning a programme for physical activity promotion among university students.

\section{Methods}

The study was carried out in Mansoura University, Egypt, 1 month before examinations during the academic year 2007-08. Mansoura University is one of the biggest public universities in Egypt and has specialized medical centres which provide both medical and academic services. The main campus in Mansoura comprises 13 faculties; 4 faculties are located off campus. A total of 124386 students were enrolled in all faculties in 2007-08.

Students of Mansoura University were the target population. Colleges outside the city were not included for logistic reasons. Only a few (3) students with chronic disease or disability were also excluded. This was determined as self-reported by students.

Verbal approval was obtained from the authorities of each college to conduct the survey in the setting as there is no research ethics committee at the moment in the university. After obtaining approval for data collection, the researchers introduced themselves to the students in each cluster and informed them about the aim of the study and about guarantees of anonymity and confidentiality. Students were allowed to respond in their own time and in private. Participation was entirely on voluntary basis after giving verbal consent.

\section{Study tool}

An anonymous, self-administered questionnaire was used to collect data on sociodemographic characteristics, membership in sports clubs, and physical activity using an Arabic language translation of the long form of the International Physical Activity Questionnaire (IPAQ) [14].
A list of potential barriers to physical activity/sports participation was prepared and students required answering whether these are not barriers, permanent barriers or temporary barriers. Opinions about the potential benefits of physical activity and suggestions to promote physical activity among university students were also included in the questionnaire.

The long form of IPAQ is used to collect data on physical activity levels among young and middle age adults (15-69 years) over the previous 7 days. This version provides detailed information for evaluation purposes. The reliability and validity of the questionnaire were tested across 12 countries (14 sites) in 2000. The findings suggest that it has acceptable properties for use in many settings and in different languages, and is suitable for national populationbased prevalence studies of participation in physical activity $[15,16]$.

The long form of the IPAQ questionnaire was translated into Arabic separately by 2 bilingual translators (first 2 authors). The 2 versions were combined and revised and then back translated into English by the last 2 authors. The translation was refined after back translation until agreement was obtained among the 4 translators. Seven bilingual experts (staff members of Department of Public Health, College of Medicine, Mansoura University) examined the Arabic version of the questionnaire for content and construct validity and agreed upon it. A list of possible barriers to physical activity was developed by the authors and approved by the staff members. The questionnaire was then piloted for comprehension and ease of administration.

\section{Pilot study}

A pilot study was done on 50 university students attending the University Students' Hospital for inconsequential conditions e.g. acne, blood donation. During this pilot study the Arabic version of the IPAQ and the list of barriers 
were tested and the level of physical inactivity was used to calculate the sample size for the full scale study. The Arabic version was retested on 41 of the same students who attended for follow-up after 1 week. The test-retest correlation coefficients ranged from 0.73 to 0.87 for the total physical activity score and the domain-specific score and activity specific scores.

\section{Study variables}

The outcome variables are the total physical activity score, domain-specific scores, activity-specific scores and physical activity levels.

The predictor variables were age in years, sex, college, residence (urban or rural), education and work of father and mother, and membership of sports club or participating in university sports activities. Social score and socioeconomic status were calculated according to Fahmy and El-Sherbini [17], which incorporates parent's education and work, family income and number of persons per room within the home.

Students were asked to think about all the vigorous and moderate activities that they had done in the previous 7 days. Vigorous physical activities are those that take hard physical effort and make a person breathe much harder than normal. Moderate activities refer to activities that take moderate physical effort and make a person breathe somewhat harder than normal [14].

Metabolic equivalent (MET) is a unit used to estimate the metabolic cost (oxygen consumption) of physical activity. One MET equals the resting metabolic rate of approximately $1 \mathrm{kcal} /$ $\mathrm{kg} / \mathrm{h}$. MET-minutes is the rate of energy expenditure expressed as METs per minute multiplied by minutes of a specific activity [18].

\section{Sampling}

Sample size was calculated using EpiInfo, version 6.02. According to the student affairs administration, the total number of registered students on the main campus was 109067 . The pilot study showed that about $10 \%$ of students were physically inactive. With the worst acceptable level $8.5 \%$, the sample needed for the study was estimated to be about 1515 students at a study power of $80 \%$ and $95 \%$ confidence level. To overcome the attrition due to cluster sampling, $10 \%$ was added to the sample size giving a final sample size of 1667 .

A multistage, stratified, cluster sampling technique was adopted. In the first stage the university colleges were stratified into medical (medicine, pharmacy, dentistry, veterinary and nursing), other practical (engineering, agriculture, physical education) and non-practical/theoretical (education, commerce, law, arts). The sample size was distributed proportionally between these 3 categories. In the second stage, 1 college or more was selected from each group. Lastly, in each college students were stratified into the different academic years. From each year a section or group (cluster) was randomly chosen. All students in the chosen clusters were included. A total of 1885 students were registered in 47 chosen clusters (40-50 students in each cluster). The response rate was $90.6 \%$ (1708 out of 1885 ). Reasons for non-participation were absence during the study period (3.8\%), incomplete questionnaires (3.3\%) and lack of interest in the study (2.2\%).

\section{Data analysis}

Using the Ainsworth et al. compendium of the average MET score for each type of activity [18], the following values were used for the analysis of IPAQ data: walking at work $=3.3 \mathrm{MET}$, cycling for transportation $=6.0 \mathrm{METs}$, moderate yard work $=4.0$ METs and vigorous intensity in leisure $=8.0 \mathrm{METs}$ [16].

Data were analysed using SPSS, version 16. Descriptive statistics were presented as mean and standard deviation (SD), first, second (median) and third quartiles (Q1, Q2 and Q3) of total physical activity score, domain-specific scores and activity-specific scores as proposed by IPAQ Research Committee [16]. Physical activity scores and levels were calculated according to the guidelines for data processing and analysis of the IPAQ. Continuous scores were expressed as MET-minutes per week (MET level $\times$ minutes of activity/ day $x$ days per week) [16].

In categorical data, the Chi-squared test was used for comparison between groups. Significant factors predicting of physical inactivity on bivariate analysis were entered into multivariate logistic regression analysis to find out the independent predictors of physicalinactivity. Odds ratio and $95 \%$ confidence interval was calculated. $P<0.05$ was considered statistically significant.

\section{Results}

Age of participating students ranged from 17 to 25 years, with a mean of 19.6 (SD 1.6) years. About half(49.9\%) were males and $54.9 \%$ were rural residents.

\section{Pattern of physical activity}

Total physical activity score, domainspecific scores and activity-specific scores were non-parametric (skewed) in distribution. The total physical activity score ranged from 0 to 32928.0 (mean 3133.0; median 2256.0) MET-min/ week. The highest median score was observed in the walking domain, while domestic and gardening activities had the lowest median score. Regarding the activity levels, $11.3 \%$ of students were physically inactive, $52.0 \%$ had moderate and $36.7 \%$ had high physical activity levels (Table 1).

\section{Predictors of physical inactivity}

In bivariate analysis, sex, grade, college, residence, participation in university sports activities, membership of sports clubs, father's and mother's education level, family income and socioeconomic standards were significant predictors of physical inactivity. The non-significant 


\begin{tabular}{|c|c|c|c|}
\hline Physical activity \& domain & Min-max & Median (IQR) & Skewness \\
\hline Total physical activity score (MET-min/wk) & $0-32928$ & $2256(91-4111)$ & 2.77 \\
\hline \multicolumn{4}{|l|}{ Domain-specific score (Total MET-min/wk) } \\
\hline At work & $0-24906$ & $594(120.0-1491)$ & 3.94 \\
\hline For transportation & 0-13104 & $346(132.0-738)$ & 3.71 \\
\hline From domestic \& gardening activities & $0-6600$ & $60(0-488)$ & 3.27 \\
\hline In leisure time & 0-11016 & $264(0-982)$ & 3.1 \\
\hline \multicolumn{4}{|l|}{ Activity specific score (total MET-min/wk) } \\
\hline Walking & $0-13068$ & $1023(0-1848)$ & 2.45 \\
\hline Moderate & $0-16980$ & $405(0-1260)$ & 3.53 \\
\hline Vigorous & $0-23520$ & $0(0-840)$ & 4.42 \\
\hline Physical activity level & \multicolumn{2}{|c|}{ No. } & $\%$ \\
\hline Low & \multicolumn{2}{|c|}{193} & 11.3 \\
\hline Moderate & \multicolumn{2}{|c|}{889} & 52.0 \\
\hline High & \multicolumn{2}{|c|}{626} & 36.7 \\
\hline
\end{tabular}

$I Q R=$ inter quartile range (first-third quartiles).

MET-min $/$ wk = metabolic equivalent-minute $/$ week.

independent variables were age, parent's work and family size (Table 2). The independent predictors of physical inactivity as revealed by logistic regression analysis are presented in Table 3. Females were about 2 times more likely to be physically inactive than males, also students of the college of medicine were more likely to be physically inactive $(\mathrm{OR}=1.8)$, while students of physical education were the least likely to be physically inactive $(\mathrm{OR}=0.1)$. Nonmembership of sports clubs was associated with greater physical inactivity $(\mathrm{OR}=1.6)$. Students of high social class families were about 2 times more likely to be physically inactive compared to those with low/very low social class.

\section{Barriers to physical activity}

No barriers to physical activity were reported by $63(3.7 \%)$ students. The perceived barriers reported are listed in Table 4. The commonest permanent barriers were time limitation, lack of accessible and suitable sporting places and lack of support and encouragement from others. The commonest temporary barriers were not being interested in sports, time limitation, unsuitable (hot or cold) weather and feeling tired on physical activity.

\section{Benefits of and suggestions for promoting physical activity}

The commonest perceived benefits of physical activity were promotion and maintenance of health, improving body image and shape, improving muscle power, spending free time, weight control and psychological wellbeing (Table 5). More than two-thirds of the students suggested the provision of free playgrounds in each college to practice sports during free time to promote physical activity in the university.

\section{Discussion}

This study showed that $11.3 \%$ of participants were physically inactive, much lower than the $45.8 \%$ of college students in a Saudi Arabian study [19]. Only 26.4\% of university students in a Lebanese study were engaged in physical exercise [20]. About one-third of Chinese and Brazilian university students were physically inactive $[21,22]$. Makrides et al. [23] reported that fewer than half of university students in Canada participated in exercise 3 or more times per week. A previous study in the USA [24] found that only $39 \%$ of students exercised 3 or more times per week. Another American study reported that $47 \%$ of college students did not engage in vigorous physical activity and $17 \%$ were physically inactive [25]. The National College Health Risk Behavior Survey (NCHRBS) in the USA reported that $42 \%$ of college students participated in vigorous activity at least 3 times a week, while an additional 20\% participated in moderate activity [26]. Staten et al. reported that $39 \%$ and $41 \%$ of university students were vigorously and moderately physically active [27]. National statistics also show that in many countries at least one-quarter of all young people are deemed physically inactive [28]. Among university students of 23 countries the prevalence of inactivity in leisure time varied with cultural and economic development factors, averaging 23\% (northwestern Europe and USA), 30\% (central and eastern Europe), 39\% (Mediterranean), $42 \%$ (Pacific Asia), and 44\% (developing countries) [11]. This variation in the level of physical inactivity between different countries is a reflection of socioeconomic development, technology and urbanization.

Analysis of the risk factors of physical inactivity using regression analysis 


\begin{tabular}{|c|c|c|c|}
\hline Predictor & Total & $\begin{array}{c}\text { Physically inactive } \\
\text { No. (\%) }\end{array}$ & OR $(95 \% \mathrm{Cl})$ \\
\hline Overall & 1708 & $193(11.3)$ & \\
\hline \multicolumn{4}{|l|}{ Age (years) } \\
\hline$<20$ & 768 & $93(12.1)$ & $1.2(0.9-1.6)$ \\
\hline $20+$ & 940 & $100(10.6)$ & Ref \\
\hline \multicolumn{4}{|l|}{ Sex } \\
\hline Female & 856 & $123(14.4)$ & $1.1(1.4-2.6)$ \\
\hline Male & 852 & $70(8.2)$ & Ref \\
\hline \multicolumn{4}{|l|}{ Grade } \\
\hline Preparatory and first & 319 & $53(16.6)$ & $1.0(0.5-1.8)$ \\
\hline 2nd & 714 & 83(11.6) & $0.6(0.4-1.1)$ \\
\hline $3 r d$ & 307 & $23(7.5)$ & $0.4(0.2-0.8)$ \\
\hline 4 th & 264 & $16(6.1)$ & $0.3(0.1-0.7)$ \\
\hline 5 th \& 6th & 104 & 18(17.3) & Ref \\
\hline \multicolumn{4}{|l|}{ College } \\
\hline Medicine & 331 & $64(19.3)$ & $1.5(0.9-2.5)$ \\
\hline Engineering & 282 & $37(13.1)$ & $1.0(0.6-1.7)$ \\
\hline Physical education & 247 & $2(0.8)$ & $0.1(0.01-0.2)$ \\
\hline Education & 229 & $11(4.8)$ & $0.3(0.2-0.7)$ \\
\hline Law & 211 & 23 (10.9) & $0.8(0.4-1.4)$ \\
\hline Arts & 196 & $27(13.8)$ & $1.1(0.6-1.9)$ \\
\hline Commerce & 212 & $29(13.7)$ & Ref \\
\hline \multicolumn{4}{|l|}{ Residence } \\
\hline Urban & 771 & $111(14.4)$ & $1.8(1.3-2.4)$ \\
\hline Rural & 937 & $82(8.8)$ & Ref \\
\hline \multicolumn{4}{|l|}{ University sports activity } \\
\hline No & 1415 & $171(12.1)$ & $1.7(1.0-2.8)$ \\
\hline Yes & 293 & $22(7.5)$ & Ref \\
\hline \multicolumn{4}{|l|}{ Membership of sports clubs } \\
\hline No & 1223 & $162(13.2)$ & $2.2(1.5-3.4)$ \\
\hline Yes & 485 & $31(6.4)$ & Ref \\
\hline \multicolumn{4}{|l|}{ Father's work } \\
\hline Professional/employee & 1131 & $132(11.7)$ & $1.0(0.6-1.5)$ \\
\hline Farmer/manual worker & 295 & $27(9.2)$ & $0.7(0.4-1.3)$ \\
\hline Other & 282 & $34(12.1)$ & Ref \\
\hline \multicolumn{4}{|l|}{ Father's education } \\
\hline$<$ Secondary & 952 & $134(14.1)$ & $1.7(1.1-2.8)$ \\
\hline Secondary & 456 & $33(7.2)$ & $0.8(0.5-1.5)$ \\
\hline > Secondary & 300 & $26(8.7)$ & Ref \\
\hline \multicolumn{4}{|l|}{ Mother's work } \\
\hline Housewife & 871 & $101(11.6)$ & $1.1(0.8-1.5)$ \\
\hline Working outside the home & 837 & $92(11.0)$ & Ref \\
\hline \multicolumn{4}{|l|}{ Mother's education } \\
\hline$<$ Secondary & 736 & $112(15.2)$ & $1.6(1.1-2.4)$ \\
\hline Secondary & 598 & $43(7.2)$ & $0.7(0.4-1.1)$ \\
\hline$>$ Secondary & 374 & $38(10.2)$ & Ref \\
\hline \multicolumn{4}{|l|}{ Family size } \\
\hline$<6$ persons & 906 & 113 (12.5) & $1.3(0.9-1.8)$ \\
\hline $6+$ persons & 802 & $80(10.0)$ & r \\
\hline \multicolumn{4}{|l|}{ Family income } \\
\hline Able to save & 732 & $104(14.2)$ & $2.3(1.2-4.7)$ \\
\hline Enough & 811 & $78(9.6)$ & $1.5(0.8-3.0)$ \\
\hline Not enough & 165 & $11(6.7)$ & Ref \\
\hline \multicolumn{4}{|l|}{ Socioeconomic standard } \\
\hline High & 599 & $98(16.4)$ & $2.3(1.6-3.2)$ \\
\hline Middle & 396 & $38(9.6)$ & $1.2(0.8-1.9)$ \\
\hline Low \& very low & 713 & $57(8.0)$ & Ref \\
\hline
\end{tabular}

$O R=$ odds ratio; $C l=$ confidence interval; Ref $=$ reference group . 


\begin{tabular}{|c|c|c|c|}
\hline Predictor & $\beta$ & $P$ & OR $(95 \% \mathrm{Cl})$ \\
\hline \multicolumn{4}{|l|}{ Sex } \\
\hline Female & 0.6 & $\leq 0.001$ & $1.8(1.3-2.5)$ \\
\hline Male & - & & Ref \\
\hline \multicolumn{4}{|l|}{ College } \\
\hline Medicine & 0.6 & 0.04 & $1.8(1.02-3.3)$ \\
\hline Engineering & 0.1 & 0.8 & $1.1(0.6-2.1)$ \\
\hline Physical education & -2.5 & 0.001 & $0.1(0.0-0.4)$ \\
\hline Education & -0.7 & 0.07 & $0.5(0.2-1.1)$ \\
\hline Law & 0.2 & 0.6 & $1.2(0.6-2.3)$ \\
\hline Arts & 0.4 & 0.2 & $1.5(0.8-3.0)$ \\
\hline Commerce & - & & Ref \\
\hline \multicolumn{4}{|c|}{ Membership of sports clubs } \\
\hline No & 0.5 & 0.04 & $1.6(1.0-2.5)$ \\
\hline Yes & - & & Ref \\
\hline \multicolumn{4}{|l|}{ Socioeconomic standards } \\
\hline High & 0.7 & $\leq 0.001$ & $2.1(1.4-3.1)$ \\
\hline Middle & 0.2 & 0.4 & $1.2(0.8-1.9)$ \\
\hline Low/very low & - & & Ref \\
\hline Constant & \multicolumn{3}{|c|}{-2.7} \\
\hline Model $\chi^{2}$ & \multicolumn{3}{|c|}{$125.3 ; P \leq 0.001$} \\
\hline Correctly predicted (\%) & \multicolumn{3}{|c|}{88.7} \\
\hline
\end{tabular}

$O R=$ odds ratio; $C l=$ confidence interval; $R e f=$ reference group .

revealed that females were about 2 times more likely to be physically inactive than males. The same finding has been reported by many studies in different cultures and different age groups [9,11,21,29-32]. In traditional communities, females face social pressures that have historically linked physical power and athleticism to maleness: femininity is not consistent with vigorous activity and sport play. Cultural norms and values in Egypt are more permissive for boys and restrict females to the domestic domain [33].

Membership in sports clubs and coming from a family of high socioeconomic status were significant independent predictors of the high likelihood of physical inactivity. Similar findings have been reported in the USA and Hong Kong, where daily participation of adolescents in school physical education classes, use of recreation centres, high maternal education, and high family income were all associated with high level of physical activity [22,34]. In contrast to our findings, low socioeconomic standard was related to sedentary behaviour and low levels of physical activity [35].

In the present study, medical students were about 2 times more likely to be physically inactive while students of physical education were less likely to be physically inactive compared to students of commerce. This is a direct reflection of the physical education practical curricula implemented in this college.

There are 2 cognitive variables, which account for physical activity levels: perceived benefits and perceived barriers. Perceived benefits can positively improve participation in physical activity while, barriers can negatively influence it [36]. Only a minority of the students in our study reported no barriers. Time limitation (permanent or temporary) was by far the most important barrier to physical activity. The most cited temporary barriers were lack of interest in physical activity, having other important priorities and unsuitable weather. These were more or less similar to findings reported by other studies where lack of time due to busy lesson schedule, parents giving academic success priority over exercise, lack of time due to responsibilities related to family and social environment, lack of available / convenient facilities, injuries, health condition, perceived lack of support from parents and peers who were concerned more about students' academic performance than their participation in physical activity were the most cited items for physical activity barriers [30,35-37] It seem that parents and caregivers play a key role in creating a culture in the home and community that is supportive of participation in physical activity by children and young people [31].

People are more active when they can easily access key destinations such 


\begin{tabular}{|c|c|c|c|c|}
\hline \multirow[t]{2}{*}{ Barrier } & \multicolumn{2}{|c|}{ Permanent } & \multicolumn{2}{|c|}{ Temporary } \\
\hline & No. & $\%$ & No. & $\%$ \\
\hline Time limitation & 703 & 41.2 & 606 & 35.5 \\
\hline Lack of accessible and suitable sports place & 606 & 35.5 & 400 & 23.4 \\
\hline Lack of safe sporting places & 545 & 31.9 & 379 & 22.2 \\
\hline Lack of support and encourage from others & 534 & 31.3 & 415 & 24.3 \\
\hline Lack of friends to encourage me & 493 & 28.9 & 407 & 23.8 \\
\hline Have other important priorities & 475 & 27.8 & 578 & 33.8 \\
\hline Lack of sports programme that suits my physical fitness & 442 & 25.9 & 435 & 25.5 \\
\hline Not interested in sports & 429 & 25.1 & 694 & 40.6 \\
\hline Lack of motivation & 418 & 24.5 & 469 & 27.5 \\
\hline High cost & 378 & 22.1 & 411 & 24.1 \\
\hline Lack of sports skills & 344 & 20.1 & 388 & 22.7 \\
\hline Fear of failure in sports competition & 319 & 18.7 & 462 & 27.0 \\
\hline Fear of injury & 286 & 16.7 & 379 & 22.2 \\
\hline Fear of deterioration of physical illness & 282 & 16.5 & 189 & 11.1 \\
\hline No person caring for my family & 264 & 15.5 & 242 & 14.2 \\
\hline Feeling tired on physical activity & 244 & 14.3 & 514 & 30.1 \\
\hline Ignorance about benefits of sports & 241 & 14.1 & 345 & 20.2 \\
\hline Prefer to not attend to sports places & 240 & 14.1 & 244 & 14.3 \\
\hline Lack or low physical power & 238 & 13.9 & 481 & 28.2 \\
\hline Feeling of inability to practice sports adequately & 235 & 13.8 & 486 & 28.5 \\
\hline Objection of parents & 228 & 13.3 & 347 & 20.3 \\
\hline Body cannot tolerate physical activity & 216 & 12.6 & 270 & 15.8 \\
\hline Previous failure in sports competition & 187 & 10.9 & 427 & 25.0 \\
\hline Unsuitable (hot or cold) weather & 178 & 10.4 & 525 & 30.7 \\
\hline Previous bad experience with physical sports activity & 150 & 6.1 & 446 & 26.1 \\
\hline
\end{tabular}

as parks, green spaces, work places and shops. Other barriers to active living include fear of crime, road safety, transport emissions and pollution; problems with access and/or lack of recreation and sports facilities; and negative attitude to physical activity and public transport [32].

In this study, the majority of students reported 1 or more benefits of physical activity, especially the promotion and maintenance of health. In contrast, Haase et al [11] reported that knowledge about activity and health was disappointing, with only $40 \%-60 \%$ being aware that physical activity was relevant to risk of heart disease. Physical activity is consistently associated with fewer symptoms of anxiety and depression, fewer self-reported sleep problems, improved sleep quality and improved social well-being [31,38-40].

This study has 2 important features. First our findings may shed light on interventions that would promote physical activity in university students. Second, it highlights levels, barriers to and perceived benefits of physical activity in Egyptian youth for the first time. However it has some limitations. The study was carried out in students of single university during the academic year. The levels of physical activity may differ in other youth groups and may vary during vacations and the time of examinations. University students are better educated and may be more aware about benefits of physical activity than other young people. Only simple health beliefs were measured in this study, but many cognitive and attitudinal factors are known to correlate with physical activity, and examining a broader range of psychosocial variables may help to explain the motives behind the practice of physical activity.

Taking into account the significance of the college years as a transition from adolescence to adulthood, physical activity at the university should be encouraged as a preventive measure against chronic diseases and to improve quality of life through adult and elderly life. There is a need for clear, practical guidelines for practising physical 


\begin{tabular}{|c|c|c|}
\hline Benefit/suggestion & No. & $\%$ \\
\hline \multicolumn{3}{|l|}{ Perceived benefit } \\
\hline No benefits & 119 & 7.0 \\
\hline Promote and maintain health & 1202 & 70.4 \\
\hline Improve body image and shape & 953 & 55.8 \\
\hline Improve muscle power & 950 & 55.6 \\
\hline Spent free times & 905 & 53.0 \\
\hline Weight control/obesity prevention & 898 & 52.6 \\
\hline Psychological wellbeing & 864 & 50.8 \\
\hline Recreation & 786 & 46.0 \\
\hline Prevent diseases ${ }^{\mathrm{a}}$ & 861 & 50.4 \\
\hline Improve mentality and intellectuality & 772 & 45.2 \\
\hline Companionship with others & 719 & 42.1 \\
\hline Socializing & 588 & 34.4 \\
\hline Other ${ }^{b}$ & 88 & 6.2 \\
\hline \multicolumn{3}{|l|}{ Suggestions to promote physical activity } \\
\hline No suggestions & 135 & 7.9 \\
\hline Free playgrounds in each college to practice sports during free time & 1143 & 66.9 \\
\hline Educating students about benefits of physical activity & 742 & 43.4 \\
\hline Include sports education in curricula & 551 & 32.3 \\
\hline Other $^{c}$ & 207 & 12.1 \\
\hline
\end{tabular}

Categories not mutually exclusive.

${ }^{a}$ e.g. diabetes mellitus, cardiac diseases and hypertension.

${ }^{b}$ Fun and enjoyment (59), improve sleeping (14), self-dependence (10), relieve tension (5).

'Low fees for membership in youth and university sports clubs (114), separate playground for males and females (61), sports training (10), organizing monthly sports day (6), care for sports injuries (9), more incentives for sports participation (7).

activity in university students. Factors identified as predictors of physical inactivity should be taken into account in the design of interventions. University curricula should include the opportunity for all students to participate in physical activity. More research on effective strategies to promote all forms of physical activity is needed. Provision of free playgrounds in each college to practise sports during free times would promote physical activity among university students.

In conclusion the majority of students of Mansoura University are either moderately or highly physically active and perceive the benefits of physical activity. Despite these findings, there are many barriers to physical activity. Overcoming these barriers together with consideration of students' suggestions may contribute to a further increase in their level of physical activity.

\section{References}

1. Foster C. Guidelines for health-enhancing physical activity promotion programmes. Tampere, Finland, UKK Institute for Health Promotion Research, 2000.

2. Riddoch C. Physical activity. In: Ewles L, ed. Key topics in public health. Essential briefings on prevention nd health promotion. Edinburgh, Elsevier Churchill Livingstone, 2005:103-117.

3. Physical activity and health in Europe: evidence for action. Copenhagen, World Health Organization Regional Office for Europe, 2006.

4. Chobanian AV et al. 7th report of the Joint National Committee on Prevention, Detection, Evaluation, and Treatment of High Blood Pressure. Journal of the American Medical Association, 2003, 289(19):2560-2571.
5. Farrell SW, et al. Influences of cardiorespiratory fitness levels and other predictors of cardiovascular disease mortality in men. Medicine and Science in Sports and Exercise, 1998, 30:899-905.

6. Lee IM, Paffenbarger RSJr. Physical activity and stroke incidence: The Harvard Alumni Health Study. Stroke, 1998, 29:2049-2054.

7. Sesso HD et al. Physical activity and breast cancer risk in the College Alumni Health Study (United States). Cancer Causes and Control, 1998, 9:433-439.

8. Physical activity and health: a report of the Surgeon General. Atlanta, Georgia, Centers for Disease Control and Prevention, 1996. 
9. Irwin JD. Prevalence of university students' sufficient physica activity: a systematic review. Perceptual and Motor Skills, 2004, 98(1):927-943.

10. Irwin JD. The prevalence of physical activity maintenance in a sample of university students: a longitudinal study. Journal of American College Health, 2007, 56(1):37-42.

11. Haase A et al. Leisure-time physical activity in university students from 32 countries: associations with health beliefs, risk awareness and national economic development. Preventive Medicine, 2004, 39:182-190.

12. Leslie E et al. University campus settings and the promotion of physical activity in young adults: lessons from research in Australia and the USA. Health Education, 2001, 101(3):116-125.

13. Ziglio E. Addressing the socioeconomic determinant of healthy eating habits and physical activity levels among adolescents (Foreword). Copenhagen, World Health Organization Regional Office for Europe, 2006 (www.euro.who.int/_data/assets/ pdf_file/0005/98231/e89375.pdf, accessed 30 June 2011.

14. International Physical Activity Questionnaire (IPAQ). Long last 7 days self-administered format. For use with young and middleaged adults (15-69 years). 2002 (https://sites.google.com/site/ theipaq/, accessed 4 July 2011).

15. Booth ML. Assessment of physical activity: an international perspective. Research Quarterly for Exercise \& Sport, 2000, 71(2):S114-20.

16. IPAQ Research Committee. Guidelines for data processing and analysis of the International Physical Activity Questionnaire (IPAQ). Short and long forms. Stockholm, Karolinska Institute, 2005 (http://www.ipaq.ki.se/scoring.pdf, accessed 4 July 2011).

17. Fahmy SI, El-Sherbini AF. Determining simple parameters for social classifications for health research. Bulletin of the High Institute of Public Health, 1983, 13(5):95-108.

18. Ainsworth BE et al. Compendium of physical activities: classifications of energy costs of human physical activities. Medicine \& Science in Sports \& Exercise, 1993, 25(1):71-80.

19. Al-Hazzaa H. Physical activity patterns of college male subjects. King Saud University Journal, 1990, 2:383-396.

20. Musharrafieh $U$ et al. Determinant of university students physical exercise: a study from Lebanon. International Journal of Public Health, 200, 53(4):208-213.

21. Abdullah ASM et al. Factors related to non-participation in physical activity among the students in Hong Kong. International Journal of Sports Medicine, 2005, 26(7):611-615.

22. Fontes ACD, Vianna RPT. Prevalence and factors related to low level physical activity among university students in a public university in the northeast region of Brazil . Revista Brasileira de Epidemiologia, [Online] 2009, 12(1):20-29.

23. Makrides L et al. A cardiovascular health needs assessment of university students living in residence. Canadian Journal of Public Health,1998, 89(3):171-175.

24. Haberman S, Luffe, D. Weighing in college students' diet and exercise behaviors. Journal of American College Health, 1998, 46(4):189-191.

25. Suminski RR et al. Physical activity among ethnically diverse college students. Journal of American College Health, 2002, 51 (2):75-80.
26. Centers for Disease Control. Youth risk behavior surveillance: National College Health Risk Behavior Survey-United States, 1995. MMWR, 1997, 46(SS-6):1-54.

27. Staten RR et al. College students' physical activity: application of an ecological perspective. American Journal of Health Studies, 2005, 20(1/2):58-65 (http://findarticles.com/p/articles/ mi_m0CTG/is_1-2_20/ai_n27869280/, accessed 4 July 2011).

28. National Youth Risk Behavior Survey 1991-2005: trends in the prevalence of physical activity. Atlanta, Georgia, Centers for Disease Control and Prevention, 2006.

29. Abdel-Aty MA et al. Health related behaviors among adolescents and youth in Assiut Governorate, Upper Egypt. Bulletin of the High Institute of Public Health, 1999, 29(3):447-474.

30. Daskapan A et al. Perceived barriers to physical activity in university students. Journal of Sports Science and Medicine, 2006, 5:615-20.

31. Active Healthy Kids Canada. Older but not wiser. Canada's future at risk. Canada's report card on physical activity for children and youth. Toronto, Canada, 2007 (http://activehealthykids.ca/ophea/activehealthykids_v2/upload/fullEnglish-Report-Card-2007.pdf).

32. Edwards P, Tsouros A. Promoting physical activity living in urban environments; the role of local governments. The solid facts. Copenhagen, World Health Organization Regional Office for Europe, 2006.

33. Shafy HE. Leisure time and its implication. In: Adolescence and state policy in Egypt, Ch VI. Cairo, Egypt, The Population Council, Regional Office for West Asia and North Africa, 1998.

34. Behavioral risk factors survey (Main report). Commissioned by surveillance and epidemiology branch centre for health protection department of health. University of Hong Kong. Hong Kong, Social Science Research Centre, 2005.

35. Al-Refaee SA, Al-Hazzaa HM. Physical activity profile of adult males in Riyadh City. Saudi Medical Journal, 2001, 22(9):784789.

36. Buckworth J, Dishman RK. Determinants of physical activity; research to application. In: Rippe J, ed. Lifestyle medicine. Malden, Massachusetts, Williston Blackwell Science, 1999, 1016-1027.

37. Gyurcsik NC et al. Copying with barriers to vigorous physical activity during transition to university. Family \& Community Health, 2004, 27(2):130-142.

38. Calfas KJ, Taylor WC. Effects of physical activity on psychological variables in adolescents. Pediatric Exercise Science, 1994, 6:406-423.

39. Brosnahan J, et al. The relation between physical activity and mental health among Hispanic and non-Hispanic white adolescents. Archives of Pediatric \& Adolescent Medicine, 2004, 158(8):818-820.

40. Food and Nutrition Board, Institute of Medicine. Adequacy of evidence for physical activity. Guidelines development: workshop summary. Washington, DC, National Academies Press, 2007 (http://www.nap.edu/catalog.php?record_id=11819, accessed 11 June 2011). 